\title{
Lazaroids and Neuroprotection: What Benefit?
}

\author{
Maria Rosaria Carratù* \\ Department of Biomedical Sciences and Human Oncology, "Aldo Moro" University of Bari, Italy
}

Submission: February 14, 2017; Published: February 22, 2017

*Corresponding author: Maria Rosaria Carratù, Department of Biomedical Sciences and Human Oncology, "Aldo Moro" University of Bari, Piazza Giulio Cesare 11, 70124 Bari, Italy, Email: mariarosaria.carratu@uniba.it

Abbreviations: SCI: Spinal Cord Injuries; LP: Lipid Peroxidation; MP: Methylprednisolone

\section{Editorial}

Acute spinal cord injuries (SCI) are among the most devastating traumatic situations and are responsible for high morbidity and mortality rates. The consequences include motor and sensory impairment as well as perturbations of intestinal, urinary and sexual functioning [1]. Chronic neuropathic pain is a common consequence of SCI, develops over time and negatively impacts quality of life, often leading to substance abuse and depression [2]. Many factors are involved in the pathogenesis of SCI. After the initial mechanical injury, the secondary lesions arise and involve a variety of processes leading to expansion of the primary lesion. These phenomena include inflammation, oedema, ischemia, electrolytic imbalance, glutamate-induced excitoxicity, apoptosis, lipid peroxidation (LP) [3]. Although many key players are involved in the secondary cascade of events, reactive oxygen-induced LP appears to play a critical role. Therefore, a neuroprotective pharmacologic strategy would aim at antagonizing oxygen radical-induced LP in a safe and effective manner. Indeed, the pharmacological therapy of SCI is actually unsatisfactory. Modest benefits from the treatment with a high dose regimen of methylprednisolone (MP), if applied early, could improve spinal cord tissue survival, thus preserving the necessary anatomic substrate for functional recovery to take place $[4,5]$.

The rationale for its use lays, at least in part, on the MP ability to limit the propagation of LP chain reactions throughout the phospholipid bilayer [6], although anti-inflammatory effects may play some role as well [4]. However, this approach is somewhat controversial on the basis of a high incidence of serious adverse effects due to immunosuppressant and metabolic effects of MP with a significantly greater risk among patients treated with high doses [7]. Based on the LP hypothesis, antioxidant drugs were hopefully tested in the attempt to find a valid therapeutic option of proven efficacy and safety. In particular, a family of steroid compounds, 21-aminosteroids or "lazaroids", were developed. Although these compounds derive from glucocorticoids, they lack glucocorticoid activity, while simultaneously retaining a propensity for cell membrane localization [8]. In fact, lazaroids were shown to scavenge lipid peroxyl radicals and to inhibit irondependent lipid peroxidation. In particular, tirilazad mesylate was selected for clinical development, as a neuroprotective agent with the expectation to benefit from a more potent LP inhibitor devoid of the glucocorticoid receptor-mediated effects that limit the clinical utility of high-dose MP.

Tirilazad mesylate was extensively studied in animal models for the prevention of neuronal damage due to head trauma, subarachnoid hemorrhage, spinal cord injury and stroke. In these systems, tirilazad can inhibit post-traumatic LP and associated pathophysiological events, thus promoting neurological recovery after acute insult. A limited activity on mechanical hypersensitivity was observed in a model of chronic SCI-induced neuropathic pain in which oxidation damage seems to play a relevant role [9]. Results of NASCIS clinical trials in SCI patients showed some evidence of efficacy comparable to MP in the absence of steroid-related side effects [10]. Hence, this non-glucocorticoid 21-aminosteroid would be safer than MP for extension of dosing beyond the temporal limit used in clinical trials. Based on the role of reactive oxygen or oxygen-radicalinduced LP in the pathophysiology of post-traumatic spinal cord degeneration, and evidence of benefits from antioxidant compounds with neuroprotective activity like MP and tirilazad, other compounds with scavenger activity were developed. One of the most critical ROS in acute SCI appears to be peroxynitrite $[11,12]$ which is formed from the combination of superoxide and nitric oxide radicals $[13,14]$. In this regard, penicillamine and 
Tempol is prototypical scavenger of peroxynitrite, and both are neuroprotective in cell culture and in vivo models of acute CNS injury.

Another promising antioxidant-based approach concerns the design of dual inhibitors of LP and neuronal NOS such as $\mathrm{BN}-80933$ that has been reported to attenuate post-traumatic and post-ischemic degeneration in in vivo models [15]. It is clear that degeneration of the spinal cord following injury is caused by a multi-factorial secondary process; hence no pharmacologic approach based on the use of a single drug can actually promote neurological recovery. Indeed, this is the case of MP or tirilazad both limiting the propagation of LP chain reactions throughout the phospholipid bilayer, regardless of the additional antiinflammatory property of MP. The benefit of MP is questioned, with concerns regarding its safety. In this regard, tirilazad that is devoid of the typical side effects of steroid therapy could more safely and efficiently inhibit post-traumatic LP compared to high dose MP. However, the pharmacological scenario emerging from a review of the literature is more extensive and comprises other compounds. For instance, anti-inflammatory agents showed benefits in humans or animals, many inhibitors of apoptosis showed benefits in in vitro studies or in animal models, GM-1 was not more effective than MP, naloxone did not show benefits $[4,5]$. Thus, there is a need to find new neuroprotective or neurorestorative treatments, possibly targeting more than one mechanism. Such a goal would appear pursuable through co-administration of different agents. However, this raises a significant challenge mainly in terms of ethical and regulatory affairs as masterfully underlined by Hall and Springer [4] in their exhaustive reappraisal.

\section{References}

1. Bydon M, Lin J, Macki M, Gokaslan ZL, Bydon A (2014) The current role of steroids in acute spinal cord injury. World Neurosurg 82(5): 848854.

2. Bair MJ, Robinson RL, Katon W, Kroenke K (2003) Depression and pain comorbidity: a literature review. Arch Intern Med 163(20): 2433-2445

3. Villa RF, Gorini A (1997) Pharmacology of lazaroids and brain energy metabolism: a review. Pharmacol Rev 49(1): 99-136.
4. Hall ED, Springer JE (2004) Neuroprotection and acute spinal cord injury: a reappraisal. NeuroRx 1(1): 80-100.

5. do Vale Ramos RC, Alegrete N (2015) The role of pharmacotherapy in modifying the neurological status of patients with spinal and spinal cord injuries. Rev Bras Ortop 50(6): 617-624.

6. Hall ED, Braughler JM (1982) Glucocorticoid mechanisms in acute spinal cord injury: a review and therapeutic rationale. Surg Neurol 18(5): 320-327.

7. Chikuda H, Yasunaga H, Takeshita K, Horiguchi H, Kawaguchi H, et al. (2014) Mortality and morbidity after high-dose methylprednisolone treatment in patients with acute cervical spinal cord injury: a propensity-matched analysis using a nationwide administrative database. Emerg Med J 31(3): 201-206.

8. Jacobsen EJ, McCall JM, Ayer DE, Van Doornik FJ, Palmer JR, et al. (1990) Novel 21-aminosteroids that inhibit iron-dependent lipid peroxidation and protect against central nervous system trauma. J Med Chem 33(4): $1145-1151$.

9. Hassler SN, Johnson KM, Hulsebosch CE (2014) Reactive oxygen species and lipid peroxidation inhibitors reduce mechanical sensitivity in a chronic neuropathic pain model of spinal cord injury in rats. J Neurochem 131(4): 413-417.

10. Bracken MB, Shepard MJ, Holford TR, Leo-Summers L, Aldrich EF, et al. (1998) Methylprednisolone or tirilazad mesylate administration after acute spinal cord injury: 1-year follow up. Results of the third National Acute Spinal Cord Injury randomized controlled trial. J Neurosurg 89(5): 699-706.

11. Bao F, Liu D (2003) Peroxynitrite generated in the rat spinal cord induces apoptotic cell death and activates caspase-3. Neuroscience 116(1): 59-70.

12.Xu J, Kim GM, Chen S, Yan P, Ahmed SH, et al. (2001) iNOS and nitrotyrosine expression after spinal cord injury. J Neurotrauma 18(5): 523-532.

13. Beckman JS (1991) The double-edged role of nitric oxide in brain function and superoxide-mediated injury. J Dev Physiol 15(1): 53-59.

14. Radi R, Beckman JS, Bush KM, Freeman BA (1991) Peroxynitriteinduced membrane lipid peroxidation: the cytotoxic potential of superoxide and nitric oxide. Arch Biochem Biophys 288(2): 481-487.

15. Chabrier PE, Auguet M, Spinnewyn B, Auvin S, Cornet S, et al. (1999) BN 80933, a dual inhibitor of neuronal nitric oxide synthase and lipid peroxidation: a promising neuroprotective strategy. Proc Natl Acad Sci USA 96(19): 10824-10829.

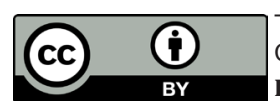

This work is licensed under Creative Commons Attribution 4.0 License DOI:10.19080/JPCR.2017.02.555582

\section{Your next submission with Juniper Publishers} will reach you the below assets

- Quality Editorial service

- Swift Peer Review

- Reprints availability

- E-prints Service

- Manuscript Podcast for convenient understanding

- Global attainment for your research

- Manuscript accessibility in different formats

( Pdf, E-pub, Full Text, Audio)

- Unceasing customer service

Track the below URL for one-step submission https://juniperpublishers.com/online-submission.php 